\title{
Vibration measures in the diagnostics of technical systems
}

\author{
Bogdan Żółtowski ${ }^{1,}{ }^{*}$, Petra Dančová ${ }^{2}$, and Jan Novosád ${ }^{2}$ \\ ${ }^{1}$ UTP University of Science and Technology in Bydgoszcz, Poland \\ ${ }^{2}$ Technical University of Liberec, Faculty of Mechanical Engineering, Department of Power \\ Engineering Equipment, Technical University of Liberec, Studentská 2, 46117 Liberec, Czech \\ Republic
}

\begin{abstract}
In the article author identifies a possible bone of mutual vibration energy measuring application used in the study of standard rail, as part of a dedicated research methodology and detailed methodologies developed in many previous author studies. Theoretical analysis and practical verification of susceptibility testing measurement information complex vibration processes indicates a possibility for their use. Recognizing the need to improve methods of machines and structures testing to assess their degradation state - this work presents important results of the research in the verification field of the proposed measures effectiveness of mutual research bench.
\end{abstract}

\section{Introduction}

Ensure the safe and trouble-free operation of machines and structures requires a search or improvement of tools, methods and techniques for non-invasive assessment of the emergency state. A common trend in recent years is the scheme and to organize various business areas targeted for specific purposes. Ensuring repeatable perform actions leading to the intended purpose it is possible, using a variety of situations dedicated research developed methodological procedures allowing for action in various areas.

The problem description and study of changes in the components destruction, materials, design and construction are carried out using the measurement of simple and complex vibration diagnostics methods based on modal analysis [14,15]. An important issue here is the description and propagation study of useful vibration energy is already widely used in diagnostic vibration and a little less used in modal analysis methods $[12,16,18]$.

In this paper the suitability test measures in the monitoring complex process of the rail connections state with the base concrete, which is associated with many problems specific railway construction. The use of composite measurements mapping the interactions measured vibration process is simpler and less subject to error than the complicated procedures simulation based on numerical methods $[9,10,20]$.

\section{Mutual measures of vibration process}

Research mutual similarities processes vibration through mutual estimators allows to specify: interdependencies between processes, correlation between sources, compliance within one process, changes in the road propagation processes in the machine and structure.

Measurement processes mutual indicate a change of source or variation in the transfer passageways signal extortion and answers. For these measures may include $[1,7,13]$ : cross-

\footnotetext{
*Corresponding author: bogzol@utp.edu.pl
} 
correlation function, coherence function, transfer function, FRF function (Frequency Response Function).

The process of measurement of the vibration are determined from the measured numerical procedures base signal, which is the value of the measured process or the two measured signals: force and the system response to put force. The concept of using vibration energy propagation of measurement uses the value of the mean square amplitude of dynamic directly proportional to the energy of the signal and written in the form [7]:

$$
U=\int_{0}^{T} x(t)^{2} d t
$$

A measure of the propagation efficiency of vibration energy $\boldsymbol{H}$ binding force signal $\boldsymbol{x}$ $(t)$ of forcing $F(t)$ takes the form:

$$
H=\frac{\int_{0}^{T} x(t)^{2} d t}{\int_{0}^{T} F(t)^{2} d t}
$$

Due to the large range of amplitudes of vibration signals is a deliberate to use logarithmic scale for comparing the numerical values of these measures:

$$
H_{\text {[log ] }}=\log (H)
$$

Large potential research opportunities create the analysis results described in the form of a matrix using measures built at different intervals integration or pre-processed waveforms.

The concept measures the propagation of vibration energy refers to the Parseval's theory [7], which indicates the identity of the signal energy presented in the time and frequency domains:

$$
\int_{-\infty}^{\infty} x^{2}(t) d t=\int_{-\infty}^{\infty}\left|X(f)^{2}\right| d f
$$

It is thus possible to define the measure of vibration energy propagation also in the frequency domain, and then the equation (2) becomes:

$$
H(f)=\frac{\int_{-\infty}^{\infty}|X(f)|^{2} d f}{\int_{-\infty}^{\infty}|F(f)|^{2} d f}
$$

In this relationship $\boldsymbol{X}(\boldsymbol{f})$ is the power spectral density of the signal force, $\boldsymbol{F}(\boldsymbol{f})$ - the power spectral density of the signal force, and $\boldsymbol{f}$ is the frequency in Hertz.

The essence of the measurement of input and response system for e designate of measures of mutual shown in Figure 1. 


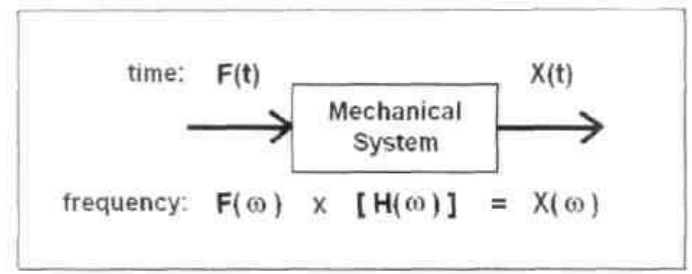

Fig.1. Model components present measurement metrics mutual.

The opportunities created by the presented approach allows to solve many technical problems during testing of real objects, which measure defined below each other are widely use $[3,5,6,11]$.

FRF - FREQUENCE RESPONCE FUNCTION

It is the function describing the frequency relation between the strength force $F(t)$ and the vibration acceleration $\boldsymbol{a}(\boldsymbol{t})$ as the response signal measured at two points in the system under study. Spectral function of transition (FRF - Frequency Response Function) can be described as a quotient of the Fourier transform vibration exciting force $F(\omega)$, the Fourier transform of the response signal $A(\omega)$

$$
F R F=\frac{\sum F(\omega)}{\sum A(\omega)}
$$

The $F R F$ as the main measure of experimental modal analysis is an inversion defined previously transmittance $H(f)$ and is referred to as real and imaginary parts. The method of its determination on the actual objects shown in Fig. 2.

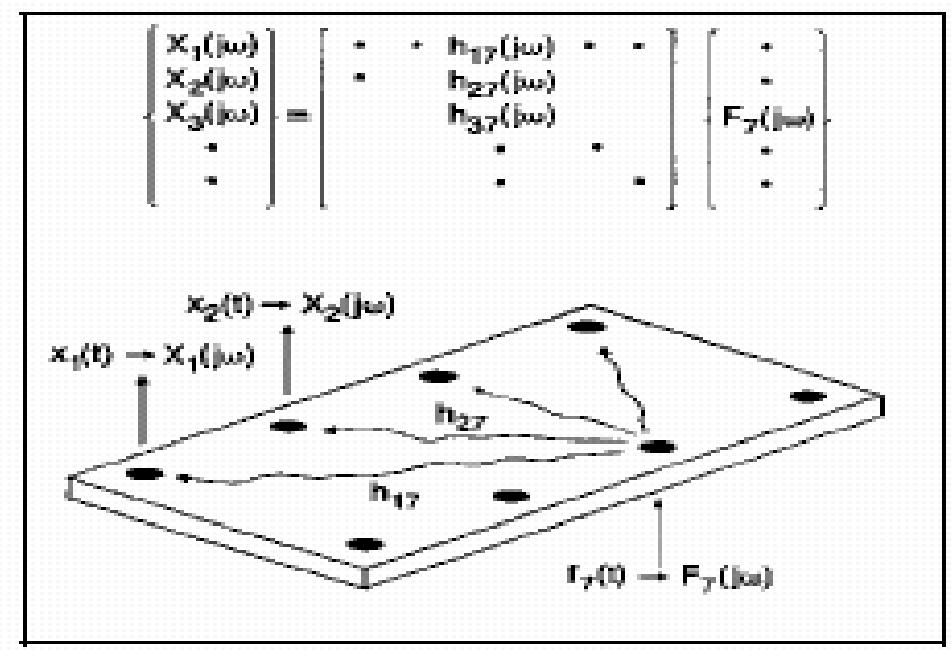

Fig.2. Research $F R F$ facility.

The $F R F$ is a complex function of the frequency, which the module shows the characteristics of amplitude - the frequency, and the argument is the angle of the phase shift between the power of forcing a response [7,13,17]. The FRF is an inversion of the transmittance, which is an important observation resulting from the analysis and testing of these measures global propagation of energy [19].

Due to the possibility of the use of force or strength kinematic introduced different characteristics depending on the nature of the physical processes the input and output, 
highlighting: the vulnerability of dynamic mobility, acceleration, dynamic stiffness, impedance and dynamic mass $[4.8,10]$.

\section{Research methodology}

Verification of the indicated measures of mutual propagation of vibration energy was carried out at a laboratory [1]. Being investigated size vibration energy flow between the points of attachment rails to the sleepers of the track has been switched on Fig. 3.

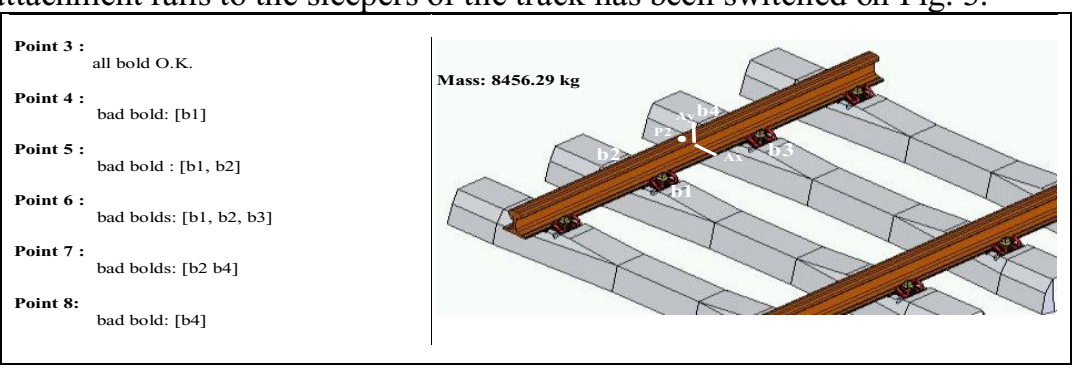

Fig. 3. Diagram of the test with the defined measuring points [1].

Using the studies measured vibration signals extortion and response software was set appropriate measure of each other, where the sample waveforms are shown in Fig. 4-6.
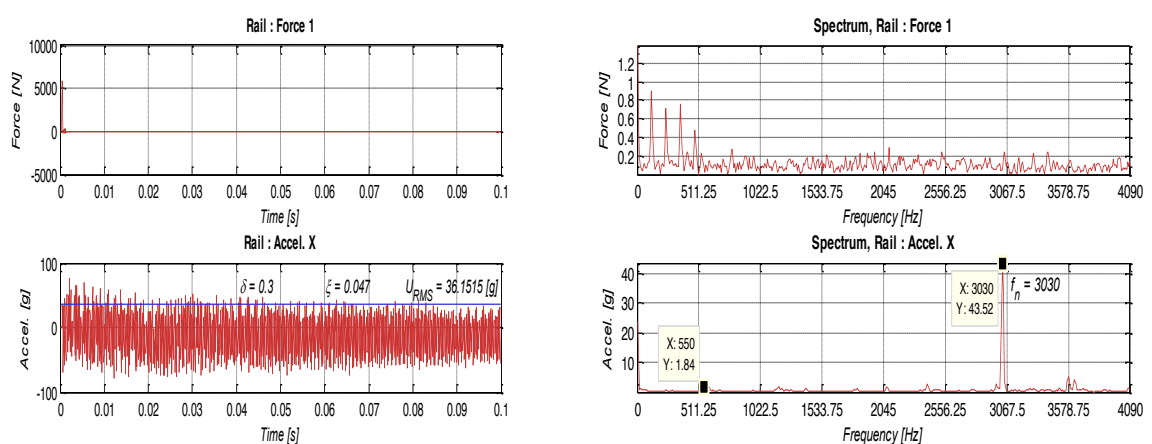

Fig. 4. Examples of the results of the exciting force and response in the time domain and frequency.
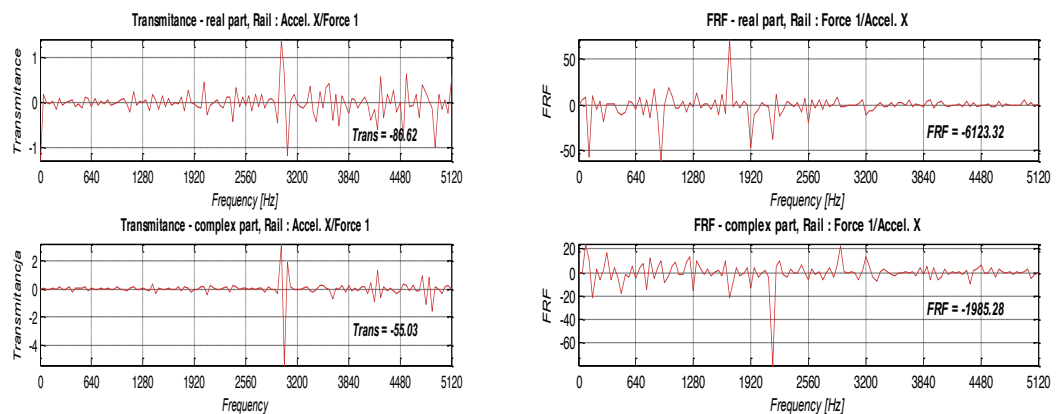

Fig. 5. The response signal and determined its coherence function 

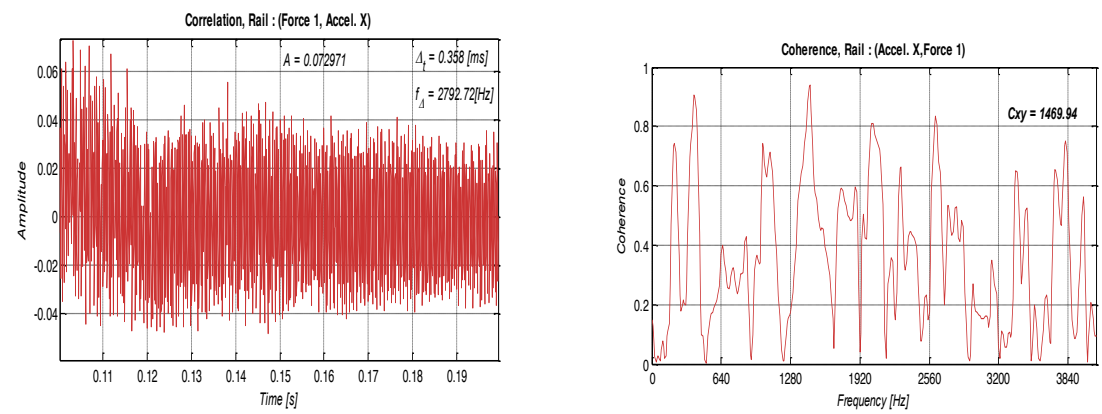

Fig. 6. Examples of waveforms transmittance and FRF.

The completed experiment studied a la the various states of attachment (pressure) between the indicated attachment points give a lot of diff s values (Table 1).

Table 1. Results of bench studies indicated measures of mutual.

\begin{tabular}{|c|c|c|c|c|c|}
\hline Reception prints & FREr & ERFu & $\mathbf{H ( f ) r}$ & $\mathbf{H}(\mathrm{f}) \mathbf{u}$ & Cohere \\
\hline $1-2$ & 288.71 & -15.05 & 137.47 & 4.91 & 197.03 \\
\hline $2-1$ & 327.21 & 248.69 & 5.67 & 4.32 & 112.65 \\
\hline $3-4$ & 163.73 & 352.91 & -3.42 & -0.54 & 89.41 \\
\hline $4-3$ & 380.32 & -29.54 & 108,18 & 11.01 & 195.27 \\
\hline $1-3$ & 83,97 & 892.43 & -9.88 & -6.97 & 109.06 \\
\hline $1-4$ & 587.91 & -15.35 & 55.93 & 1.92 & 192.37 \\
\hline $2-3$ & 456.41 & 506.42 & 7.73 & 18.02 & 139.29 \\
\hline $4-2$ & 639.01 & -118.72 & 58.17 & 10.72 & 192.04 \\
\hline $2-4$ & $1,213.83$ & 15.03 & 17,91 & 17.99 & 125.36 \\
\hline $3-1$ & 679.94 & 157.66 & 16,34 & 11.73 & 139.08 \\
\hline $3-2$ & 985.87 & -64.41 & 39.13 & 6.75 & 183.6 \\
\hline $4-1$ & 799.05 & 38.18 & 4.55 & 24.81 & 106.61 \\
\hline
\end{tabular}

Correct inference requires redundancy of information and statistical analysis to obtain a model of bonding between the assumed technical condition and the value of mutual measures. To implement this project proposed in the work of the author's methodology dedicated research facilities in the "construction" [1,2,9] uses redundancy procedures, OPTIMUM, SVD and modeling cause - effect [7,20].

Using the information contained in Table 1 processed according to the proposed methodology can confirm the good properties of measurement destruction of the cases examined the destruction of joints in order: FRFr, FRFu, $\boldsymbol{H}(\boldsymbol{f} \boldsymbol{y}, \boldsymbol{H}(f) \boldsymbol{u}$, cohere.

Considering all conducted a sensitivity analysis of the proposed measures of mutual propagation of vibration energy, using different statistical methods used in this work can continue to propose the following as the main measure of the state of destruction:

$F R F_{y}, H(f)_{R}$, cohere.

For the indicated reduction measures of destruction was determined regression model binding shown in Fig. 7. 


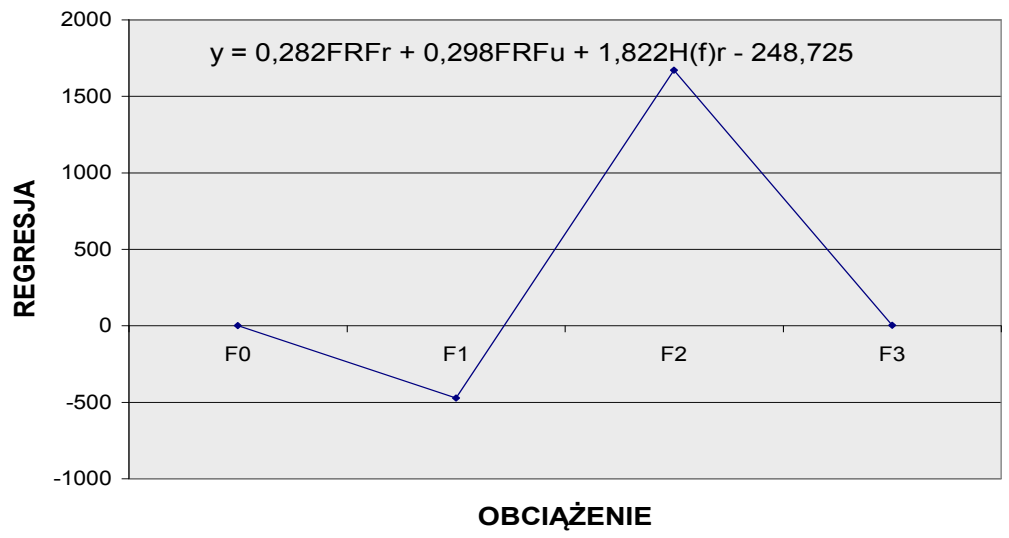

Fig.7. Model binding measures of mutual technical condition of the connection.

The presented methodology of the study allows to simplify the painstaking research conducted in the field of traditional airworthy calls on the raceways, replacing the work of many service employees to maintain fitness for work programmed utilizing available information technology proposed in this study (Fig.8).
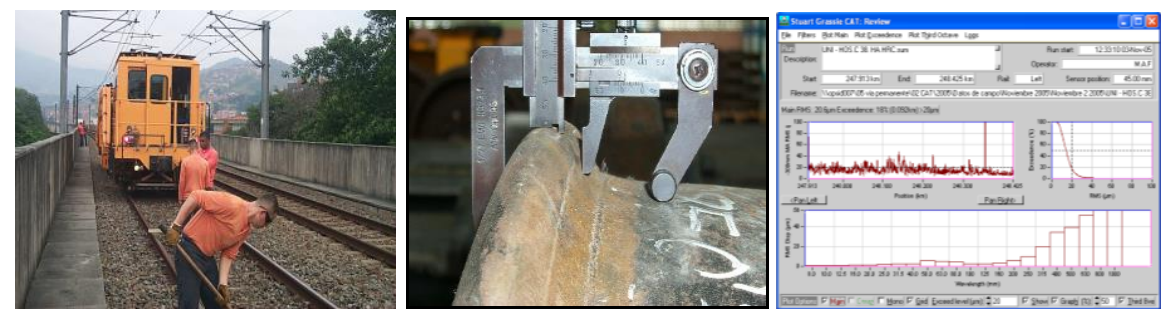

Fig.8. The modernization work of maintenance services [5]

\section{Summary}

The substance of the development includes the results shows usefulness of mutual propagation measures of vibration energy than the various forms of applications in civil engineering. The main assumption was realized by exploratory research to present the possibilities of practical use of complex estimators vibration - as a tool to solve many fundamental problems with the condition of degradation and building construction elements dynamics.

These issues, it studies exemplify dedicated to the degradation state of the construction methodology procedure for determining the physical aspects and practical applications of propagation of vibration energy measures. The proposed methodology proceedings indicate that the important role and manner of acquisition and use of vibration composite measurements in the construction industry, revealing at the same time the need to take this issue in research the destruction of existing structures. Served briefly elements of vibration theory focused on the physical aspects of the description and use of vibration estimators in the construction industry bring the issues of modeling the dynamic state of different structures and rules for their use.

Changes identification in the building structures degradation state becomes a method of assessing the structure operational status and modal analysis methods and related vibration estimates reflects well the elements degradation. 
New ways of obtaining and processing information contained in the processes of vibration often leads to improvement of various operating systems constructions, often leads to creative change existing practical solutions.

\section{References}

1. L. Castaneda, B. Zoltowski, Bases del diagnostico tecnico de maquinas. EAFIT University, Colombia (2010).

2. C. Cempel, Vibroacoustical Condition Monitoring, Ellis Ltd., New York, (1991).

3. H. Tylicki, B. Żółtowski B, Rozpoznawanie stanu maszyn. ITE - PIB, Radom (2010).

4. T. Uhl, Computer-aided identification of mechanical structure models. WNT Scientific Technical Publishers, Warszawa (1997).

5. B. Żółtowski B, L. Castaneda, Structural diagnosis of rail vehicles and method for redesign. Diagnostyka Vol.15 (3) (2014).

6. B. Żółtowski, M. Łukasiewicz, Diagnostyka drganiowa maszyn. ITE-PIB, Radom (2012).

7. B. Żółtowski, M. Łukasiewicz, T. Kałaczyński T, Techniki informatyczne w badaniach stanu maszyn. UTP Bydgoszcz (2012).

8. B. Żółtowski, M. Żółtowski M, Vibration signals in mechanical engineering and construction. ITE-PIB, Radom (2015).

9. B. Żółtowski, C. Cempel, Engineering of diagnostics machines. ITE - PIB, Radom (2004).

10. M. Żółtowski, Operacyjna analiza modalna w badaniach konstrukcji budowlanych. UTP Bydgoszcz (2012).

11. M. Żółtowski, Informatyczne systemy zarządzania $w$ inżynierii produkcji. ITE-PIB, Radom (2011).

12. M. Żółtowski M, Investigations of harbour brick structures by using operational modal analysis. Polish Maritime Research No 1/2014, (2014).

13. M. Żółtowski, B. Żółtowski B, Vibrations signal to the description of structural damage of dynamic the technical systems. XIII International Technical Systems Degradation, Conference, Liptowski Mikulesz (2015).

14. M. Żółtowski, Opis drganiowy konstrukcji budowlanych. Logistyka nr.6/2014, (2014).

15. M. Żółtowski, Investigations of harbour brick structures by using operational modal analysis. Polish Maritime Research, No. 1/(81), vol.21, (2014).

16. M. Żółtowski, M. Liss M, The use of modal analysis in the evaluation of welded steel structures. Studies and Proceedings of Polish Association for Knowledge Management, Tom 79, Bydgoszcz (2016).

17. M. Żółtowski, M. Liss, Zastosowanie eksperymentalnej analizy modalnej $w$ ocenie zmian sztywności prostego elementu konstrukcyjnego. Studies and Proceedings of Polish Association for Knowledge Management, T80, Bydgoszcz (2016).

18. M. Żółtowski, R. Martinod, Technical Condition Assessment of Masonry Structural Components using Frequency Response Function (FRF). Masonry International Journal of the International Masonry Society, Vol.29, No1 (2016).

19. M. Żółtowski, R. Martinod, Quality identification methodology applied to wallelements based on modal analysis. Civil Engineering the Athens Institute for Education and Research, Emerald, Athens (2015).

20. B. Żółtowski, M. Żółtowski, Vibrations in the Assessment of Construction State. Applied Mechanics and Materials Vol. 617 (2014). 